\title{
QUANTUM CHEMICAL SIMULATION OF THE INTERACTION OF FUNCTIONAL GROUPS IN POLYURETHANES WITH 3d-METAL IONS DURING THEIR EXTRACTION FROM AQUEOUS SOLUTIONS
}

\author{
M. A. Ksenofontov, ${ }^{a}$ E. Yu. Bobkova, ${ }^{a *}$ M. B. Shundalau, ${ }^{\text {a,b }}$ \\ L. E. Ostrovskaya, ${ }^{a}$ and V. S. Vasil'eva ${ }^{a}$
}

UDC 539.194:678.623

The interaction of the functional groups in the polyurethane foam adsorbent Penopurm ${ }^{\circledR}$ with the cations of some $3 d$-metals upon their extraction from aqueous solutions has been studied by atomic emission spectroscopy, UV/Vis and vibrational IR spectroscopy, and quantum chemical simulation using density functional theory. Penopurm ${ }^{\circledR}$ absorbs 3d-metal cations from aqueous solutions in the pH range 5-7. Some spectral criteria have been found indicating a predominant interaction of $\mathrm{Ni}^{2+}$ ions with various fragments of the polyurethane foam structure.

Keywords: polyurethane foams, adsorption of 3 d-metal salts from aqueous solutions, IR spectrum, density functional theory.

Introduction. Gasfilled crosslinked polymers, including polyurethane foams (PUF), contain two types of cells: macrocells with diameter from several tens to hundreds of microns and microcells with diameter from 0.01 to $1.0 \mathrm{~mm}$. The amount of microcells is two or three orders of magnitude greater than the amount of macrocells and the size of the microcells is virtually independent of the density of the foam [1].

A PUF adsorbent Penopurm ${ }^{\circledR}$ has been developed at the A. N. Sevchenko Institute of Applied Physical Problems, Belarusian State University [2]. The macromolecules in this product feature alternating oligoether fragments $-\mathrm{O}-\left(\mathrm{CH}{ }_{2} \mathrm{CH}_{2} \mathrm{O}\right)_{n-1}$ $\mathrm{CH}_{2} \mathrm{CH}_{2}-\mathrm{O}-$ and methylenediphenyl diisocyanate fragments linked to each other by means of urethane $(-\mathrm{NH}-\mathrm{C}(\mathrm{O}) \mathrm{O}-)$, allophonate $(-\mathrm{NH}-\mathrm{C}(\mathrm{O})-\mathrm{NR}-\mathrm{C}(\mathrm{O}) \mathrm{O}-)$, urea $(-\mathrm{NH}-\mathrm{C}(\mathrm{O})-\mathrm{NH}-)$, and biuret fragments $(-\mathrm{NH}-\mathrm{C}(\mathrm{O})-\mathrm{NR}-\mathrm{C}(\mathrm{O})-\mathrm{NH}-)$ as well as terminal isocyanate $(-\mathrm{N}=\mathrm{C}=\mathrm{O})$ and hydroxyl groups $(-\mathrm{OH})$.

The presence of open micro and macropores in the Penopurm ${ }^{\circledR}$ adsorbent as well as the chemical structure of the macromolecules with flexible nonpolar aliphatic units $-\mathrm{O}-\left(\mathrm{CH}_{2} \mathrm{CH}_{2} \mathrm{O}\right)_{n-1} \mathrm{CH}_{2} \mathrm{CH}_{2}-\mathrm{O}-$ enable it to adsorb various liquid petroleum products and other waterimmiscible hydrocarbons in amounts 20-90 times greater than the mass of the adsorbent. The porous structures of various PUF are compared in Table 1.

The macropores serve as transport channels, through which petroleum product molecules penetrate into the bulk of the adsorbent, where the molecules are held for an unlimited period due to their affinity to the nonpolar units of the foam macromolecules on account of hydrophobic interactions. Furthermore, the Penopurm ${ }^{\circledR}$ adsorbent can be used as an adsorption filtration material for the purification of industrial waste water to remove emulsified and dissolved petroleum products in order to achieve threshold limit values [3]. However, as a rule, waste water contains a large variety of pollutants such as petroleum products, heavy metal ions, and surfactants. Hence, we studied the capacity of Penopurm ${ }^{\circledR}$ to adsorb not only nonpolar compounds but also metal ions from aqueous solutions without introducing additional reagents into the solution [4].

Considerable experience has now accumulated for the use of PUF adsorbents in adsorption spectroscopy and analysis tests [6]. Dmitrienko [5,6] has noted that both unmodified and modified PUF adsorb metal ions as their acyl complexes, which are large hydrophobic singlycharged complex cations formed in aqueous solutions of mineral acids. In describing the methods for the adsorption of metal acido complexes, Dmitrienko [5, 6] stressed the multifaceted nature of this process. The most likely mechanisms include extraction, anionexchange, cationchelate, and ligand exchange or addition [5].

*To whom correspondence should be addressed.

A. N. Sevchenko Institute of Applied Physical Problems, Belarusian State University, 7 Kurchatov Str., 220045, Minsk, Belarus; email: lab_dozator@mail.ru; belarusian State University, Minsk, Belarus; email: shundalov@bsu.by. Translated from Zhurnal Prikladnoi Spektroskopii, Vol. 84, No. 5, pp. 758-766, September-October, 2017. Original article submitted December 2, 2016. 
TABLE 1. Porous Structures of Various Polyurethane Foams

\begin{tabular}{|l|c|c|c|}
\hline \multicolumn{1}{|c|}{ Index } & $\begin{array}{c}\text { Rigid PUF for heat } \\
\text { insulation }\end{array}$ & \multicolumn{2}{|c|}{ Semirigid PUF } \\
\hline Apparent density, g/cm & 0.040 & 0.015 & 0.010 \\
Actual (pycnometric) density, g/cm ${ }^{3}$ & 1.29 & 1.18 & 1.19 \\
Porosity, \% & 96.7 & 99.2 & 98.7 \\
Effective (open) porosity, \% & 0 & 98.8 & 98.3 \\
Pore diameter, $\mu \mathrm{m}$ (max/min) & $500 / 200$ & $5000 / 50$ & $5000 / 50$ \\
Air permeability coefficient, $10^{13} \mathrm{~m}^{2}$ & impermeable & 165 & 143 \\
\hline
\end{tabular}

Chemisorption processes are possible involving unmodified PUF in the complex formation of adsorbed metal ions with the functional groups of organic reagents in modified PUF [5]. The possibility of complex formation of lithium, calcium, copper, and yttrium chlorides with polyurethanes (PU) has been demonstrated by Liu et al. [7], who used vibrational IR spectroscopy to detect absorption bands characteristic for complexes.

In the present work, we carried out a theoretical and experimental study of the interaction of $3 \mathrm{dmetal}$ cations with the functional groups of Penopurm ${ }^{\circledR}$ adsorbent in adsorption from aqueous solution. A possible mechanism for this interaction, which may be elucidated by vibrational IR spectroscopy and quantum chemical simulation, is complex formation. In previous work [8-10], we used quantum chemical calculations and spectroscopic measurements to interpret the vibrational spectra of PU structural fragments [8], constructed structural models, and interpreted the vibrational spectra of uranium complexes with polar organic ligands $[9,10]$. Calculations carried out using the density functional theory (DFT) demonstrated the suitability of the models of the structure of fragments of PU and complexes as well as the accord of the experimental structural and spectral data.

Experimental and Calculations. The adsorption of ions from aqueous solutions at room temperature was studied at $\mathrm{pH}$ 5-7. The change in the concentrations of salts $\mathrm{Co}\left(\mathrm{NO}_{3}\right)_{2}, \mathrm{CuSO}_{4}$, and $\mathrm{NiSO}_{4}$ during the adsorption process under dynamic conditions was determined spectrophotometrically by measuring the optical density of the strong bands of $\mathrm{Co}^{2+}$ at $300 \mathrm{~nm}, \mathrm{Ni}^{2+}$ at $395 \mathrm{~nm}$, and $\mathrm{Cu}^{2+}$ at $800 \mathrm{~nm}$. The adsorption of salts $\mathrm{Cd}\left(\mathrm{NO}_{3}\right)_{2}, \mathrm{FeSO}_{4}, \mathrm{ZnSO}_{4}, \mathrm{Co}\left(\mathrm{NO}_{3}\right)_{2}$, and $\mathrm{CuSO}_{4}$ under steadystate conditions was studied by atomic emission analysis when the initial concentration of the salts in aqueous solution was $100 \mathrm{mg} / \mathrm{L}$.

The IR spectra of cut samples of the adsorbent saturated in an aqueous solution of $\mathrm{NiSO}_{4}$ and dried in the air as pressed thin plates were recorded using a Bruker Vertex 70 Fourier spectrophotometer at $4000-400 \mathrm{~cm}^{-1}$ (attenuated total, reflection ZnSe crystal, resolution $2 \mathrm{~cm}^{-1}$ ).

The quantum chemical calculations were carried out using the GAMESSUS program [11] in the framework of the DFT formalism. The B3LYP hybrid exchangecorrelational functional was used in all the calculations [12-14]. The effective core potential (ECP) was used to describe the nickel ion (Stuttgart ECP10MDF) [15]. In this approximation, some number (10 in this case) of core electrons are replaced by an empiricallyselected effective potential. The DZ basis set ECP10MDF $(8 \mathrm{~s} 7 \mathrm{p} 6 \mathrm{~d} 2 \mathrm{f} 1 \mathrm{~g}) \rightarrow[6 \mathrm{~s} 5 \mathrm{p} 3 \mathrm{~d} 2 \mathrm{f} 1 \mathrm{~g}]$ was used for the remaining 16 nickel ion electrons. The other atoms were described using the Dunning cc-pVDZ standard fullelectron DZ basis. The ECP and corresponding basis sets were generated using the Extensible Computational Chemistry Environment Basis Set Database [17-19]. The ORTEP program [20] was used for visualization of the results obtained.

In the first step of the calculations, a search for the stable configuration of each fragment of the PU structure and their complexes with the $\mathrm{Ni}^{2+}$ ion was carried out by gradient optimization of all the geometric parameters of the molecular system without symmetry limitation. After completion of the optimization procedure, calculations were carried out for the eigen frequencies of vibrations in the harmonic approximation and intensities in the vibrational IR spectra. The lack of imaginary frequencies in the calculated spectra indicated that the structures obtained were at a potential energy surface minimum. The vibrational bands were assigned using calculations for the potential energy distribution over the internal coordinates.

Results and Discussion. In evaluating the efficiency of adsorbents, decisive importance is found for the adsorption time, adsorption capacity, and extent of adsorbate extraction. We found that Penopurm ${ }^{\circledR}$ absorbs $\mathrm{Cd}^{2+}, \mathrm{Co}^{2+}, \mathrm{Fe}^{2+}, \mathrm{Zn}^{2+}, \mathrm{Cu}^{2+}$, and $\mathrm{Ni}^{2+}$ ions from aqueous solution. The adsorption under dynamic conditions is complete after $15 \mathrm{~min}$. The adsorption capacity of this adsorbent varies from 30 to $460 \mathrm{mg} / \mathrm{g}$ and the absorption is $23-70 \%$ depending on the initial cation concentration. 
- Adsorption capacity $100 \mathrm{~g} / \mathrm{g}$

口 Extraction, \%

$\triangle$ Distribution coefficient, rel. units

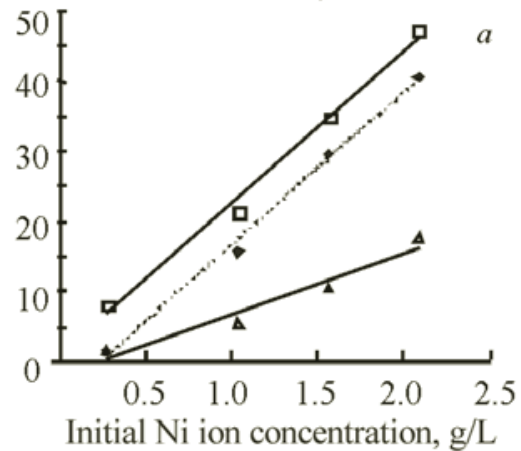

Adsorption capacity, g/g

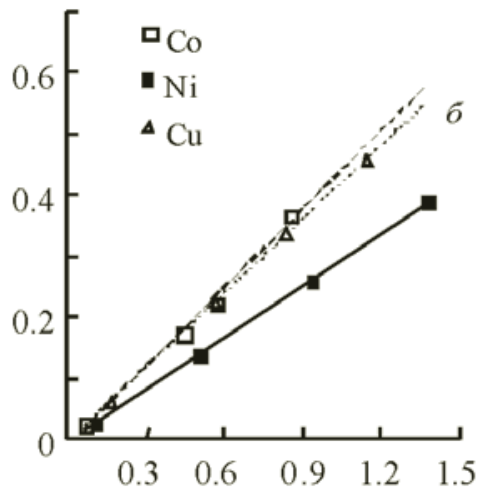

Equilibrium cation concentration, $\mathrm{g} / \mathrm{L}$

Fig. 1. Parameters for the adsorption of $3 d$-metal salts from aqueous solution.

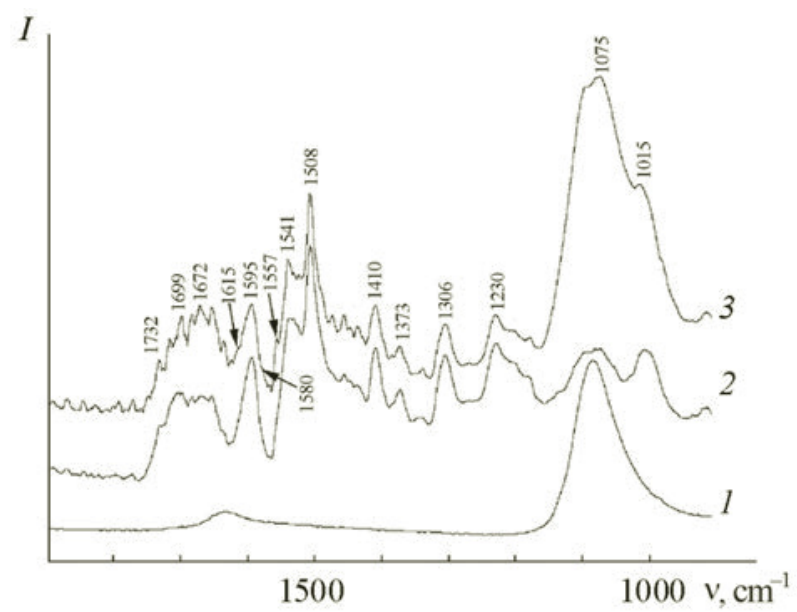

Fig. 2. IR absorption spectra of $\mathrm{NiSO}_{4} \cdot 7 \mathrm{H}_{2} \mathrm{O}$ (1), starting PUF (2), and PUF maintained in aqueous $\mathrm{NiSO}_{4}(3)$ in the region $1900-900 \mathrm{~cm}^{-1}$.

The adsorption equilibrium under steadystate conditions when the initial cation concentration is $100 \mathrm{mg} / \mathrm{L}$ is established after $30 \mathrm{~min}$ and the absorption is $99-100 \%$. The adsorption parameters for $3 d$-metal salts from aqueous solution are shown in Fig. 1.

The experimental adsorption isotherms of the salts studied shown in Fig. $1 \mathrm{~b}$ correspond to class $\mathrm{C}$ in the classification of Giles et al. [21]. This class is characteristic for adsorbents, in which the amount of adsorption sites is maintained in a broad concentration range up to the maximum possible adsorption from solution. Class $\mathrm{C}$ adsorption isotherms are seen for porous adsorbents consisting of flexible layers or regions with different crystallinity, high affinity of the adsorbate to the adsorbent, and high permeability [21].

Figure 2 shows the IR absorption spectra of $\mathrm{NiSO}_{4}$ (sample 1), starting PUF (sample 1), and PUF maintained in an aqueous solution of $\mathrm{NiSO}_{4}$ (sample 3). The spectrum of sample 3 shows the following changes: in the region $1000-1100 \mathrm{~cm}^{-1}$, a broad strong band with maximum at $1075 \mathrm{~cm}^{-1}$ assigned to absorption by $\mathrm{NiSO}_{4}$; in the region $1550-1750 \mathrm{~cm}^{-1}$, change is noted in the shape of the complex amide I band due to absorption by the carbonyl groups in the various functional groups of the polymers (urethane, urea, allophonate, and biuret groups); weak shoulders at 1580 and $1615 \mathrm{~cm}^{-1}$ appear on the band at $1595 \mathrm{~cm}^{-1}$. The structure of the amide I band in the spectra of samples 2 and 3 indicates the complex nature of the association of the carbonyl groups in the polymer as well as a possible interaction of the nickel ions with the carbonyl group oxygen atoms. We note that the absorption bands assigned by Liu et al. [7] to complex formation are found in the vicinity of $1650 \mathrm{~cm}^{-1}$ and have low intensity.

In order to elucidate the possibility of forming complexes of PU with heavy metal ions, we carried out quantum chemical calculations of the equilibrium structures and vibrational spectra for three PU fragments with typical functional groups (Fig. 3) initially in the B3LYP/cc-pVDZ approximation. Fragment I contains one phenyl group, one urethane group, 

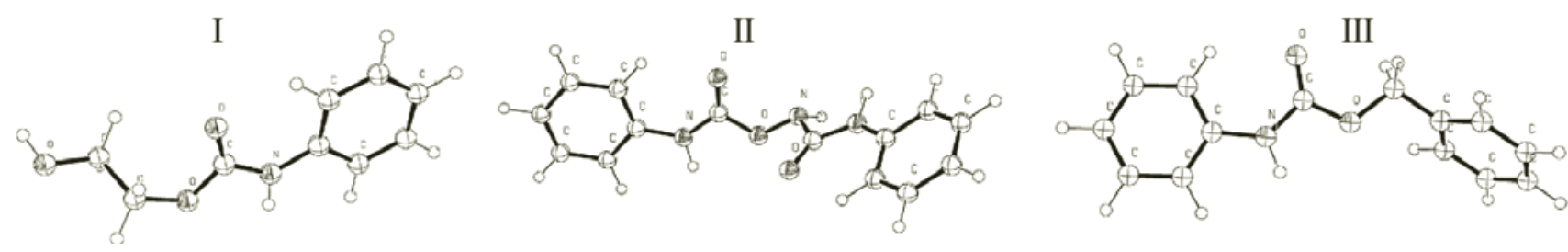

Fig. 3. Calculated structures of fragments I, II, and III.

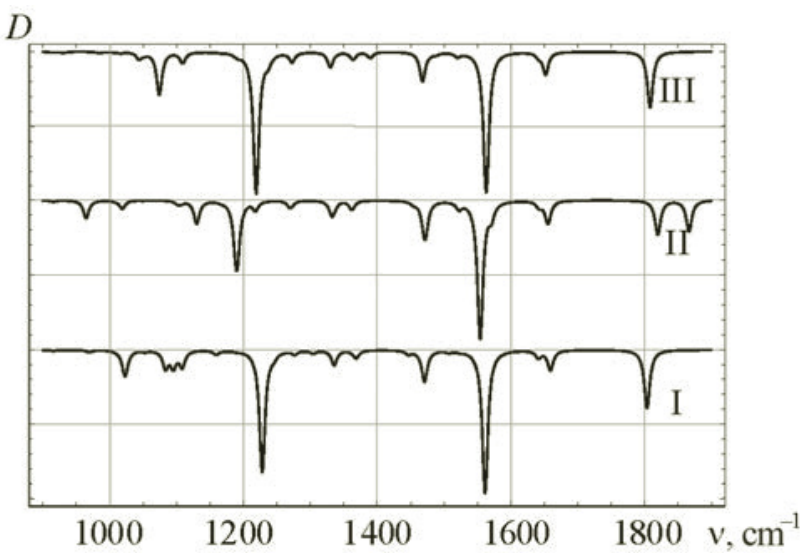

Fig. 4. Vibrational spectra of PUF fragments in the region $1900-900 \mathrm{~cm}^{-1}$ calculated in the B3LYP/cc-pVDZ approximation.

one hydroxyl group, and two methylene groups. Fragment II contains one urea group, one urethane group, and two phenyl groups. Fragment III contains one urethane group, one methylene group, and two phenyl groups. Fragment I serves as a model for complex formation with oxygen atoms of the carbonyl, ether, and hydroxyl groups. Fragment II is seen as a model for the formation of a complex with participation of the two carbonyl groups belonging to one FU chain. Fragment III is used for constructing the simplest model of complex formation with four urethane ligands. Each of the fragments contains a polar functional group such as the hydroxyl $(\mathrm{OH})$ or carbonyl group $(\mathrm{C}=\mathrm{O})$ or a heteroatom (urea group nitrogen atom or ester group oxygen atom, which may be able to interact with the metal ion.

The IR absorption spectra of fragments I, II, and III in the region $1900-900 \mathrm{~cm}^{-1}$ calculated in the harmonic approximation are shown in Fig. 4. The frequencies of the most characteristic vibrations localized in the urethane or urea groups are given in Table 2. Since the vibrations of the terminal groups such as $\mathrm{OH}, \mathrm{C}=\mathrm{O}$, and $\mathrm{NH}$ have significant anharmonicity, the calculated frequencies of the vibrations of these groups in the harmonic approximation on the theory level used are overestimated by $\sim 4-5 \%$ relative to the experimental values for the free forms [8-10]. We note that, in contrast to the localized vibrations of the terminal groups, the stretching vibrations of the $-\mathrm{O}-\mathrm{C}(\mathrm{O})-\mathrm{N}-$ fragment of the urethane group and the $-\mathrm{N}-\mathrm{C}(\mathrm{O})-\mathrm{N}-$ fragment of the urea group are delocalized. Hence, the assignment of specific bands in the spectrum to stretching modes of these fragments is somewhat arbitrary.

In contrast to fragments I and III, in which the urethane group is isolated by the phenyl and methylene groups, an interaction exists in fragment II between the urethane group and the attached urea group. This interaction results in a redistribution of the electron density localized on the $-\mathrm{O}-\mathrm{C}(\mathrm{O})-\mathrm{N}-$ fragment of the urethane group leading to significant change in the frequencies of the vibrations of this fragment (see Table 2). The strongest absorption in all the calculated spectra corresponds to the amide I, II, and III bands (Fig. 4). Taking account of the approximation used, the calculated frequencies and the absorption band intensities as well as their assignment are in accord with the experimental values [22].

Quantum chemical approximations were then carried out in the B3LYP/Stuttgart ECP10MDF+cc-pVDZ approximation for the equilibrium structures and vibrational spectra of the complexes of the $\mathrm{Ni}^{2+}$ ion with these PUF fragments. The equilibrium structures obtained for the complexes are given in Fig. 5.

The models of complexes $A, B$, and $C$ are constructed considering the coordination of the oxygen atoms of the ester, carbonyl, and hydroxyl groups (fragment $\mathrm{I}$ ) to the $\mathrm{Ni}^{2+}$ ion, respectively. Each complex is formed by a nickel ion and two fragments I. In complex $A$ (Fig. 5a), the ester group oxygen atoms and the urethane nitrogen atoms are coordinated 
TABLE 2. Frequencies $\left(\mathrm{cm}^{-1}\right)$ of the Vibrations of the Functional Groups in the PUF Fragments Calculated in the B3LYP/cc-pVDZ Approximation

\begin{tabular}{|c|c|c|c|c|}
\hline \multirow{2}{*}{ Assignment } & \multicolumn{3}{|c|}{ B3LYP/cc-pVDZ calculation } & \multirow{2}{*}{ Experiment $[22$} \\
\hline & Fragment I & Fragment II & Fragment III & \\
\hline$v(\mathrm{OH})$ & 3788 & - & - & $\begin{array}{l}3670-3580(\mathrm{~F}) \\
3400-3200(\mathrm{~A})\end{array}$ \\
\hline$v(\mathrm{NH})($ Amide $\mathrm{A})$ & 3582 (Urt) & $\begin{array}{c}3631 \text { (Urt) } \\
3571,3501 \text { (Ura) }\end{array}$ & 3624 (Urt) & $\begin{array}{l}3500-3400(\mathrm{~F}) \\
3330-3060(\mathrm{~A})\end{array}$ \\
\hline$v(\mathrm{C}=\mathrm{O})($ Amide $\mathrm{I})$ & 1804 (Urt) & $\begin{array}{c}1866(\mathrm{Urt}) \\
1820(\mathrm{M})\end{array}$ & 1808 (Urt) & $\begin{array}{l}1710-1690(\mathrm{~F}) \\
\sim 1650(\mathrm{~A})\end{array}$ \\
\hline $\begin{array}{l}v(\mathrm{CN})+\rho(\mathrm{NH}) \\
\quad \text { (Amide II) }\end{array}$ & 1561 (Urt) & $\begin{array}{c}1571,1554 \text { (Urt + Ura) } \\
1473 \text { (Ura) }\end{array}$ & 1563 (Urt) & $\begin{array}{l}1550-1510(\mathrm{~F}) \\
1570-1515(\mathrm{~A})\end{array}$ \\
\hline$v(\mathrm{CN})+\rho(\mathrm{NH})+v(\mathrm{CC})(\mathrm{Ph})$ & 1471 (Urt) & $\begin{array}{l}1470 \text { (Urt) } \\
1455 \text { (Ura) }\end{array}$ & 1468 (Urt) & $\sim 1400$ \\
\hline $\begin{array}{l}\delta(\mathrm{NH})+v(\mathrm{CN}) \\
\quad(\text { Amide III })\end{array}$ & 1228 (Urt) & $\begin{array}{l}1218 \text { (Ura) } \\
1191 \text { (Urt) }\end{array}$ & 1219 (Urt) & $1260-1240$ \\
\hline$v\left(\mathrm{O}-\mathrm{CH}_{2}\right)$ & 1095 (Urt) & - & 1074 (Urt) & $1150-1085$ \\
\hline$v(\mathrm{CN})+v(\mathrm{C}=\mathrm{O})+v(\mathrm{CO})$ & 970 (Urt) & 965 (Urt) & 984 (Urt) & $\sim 900$ \\
\hline
\end{tabular}

Note. Urt) urethane group, Ura) urea group, Ph) phenyl group, F) free form (or dilute solution), A) associated form (or solid state).

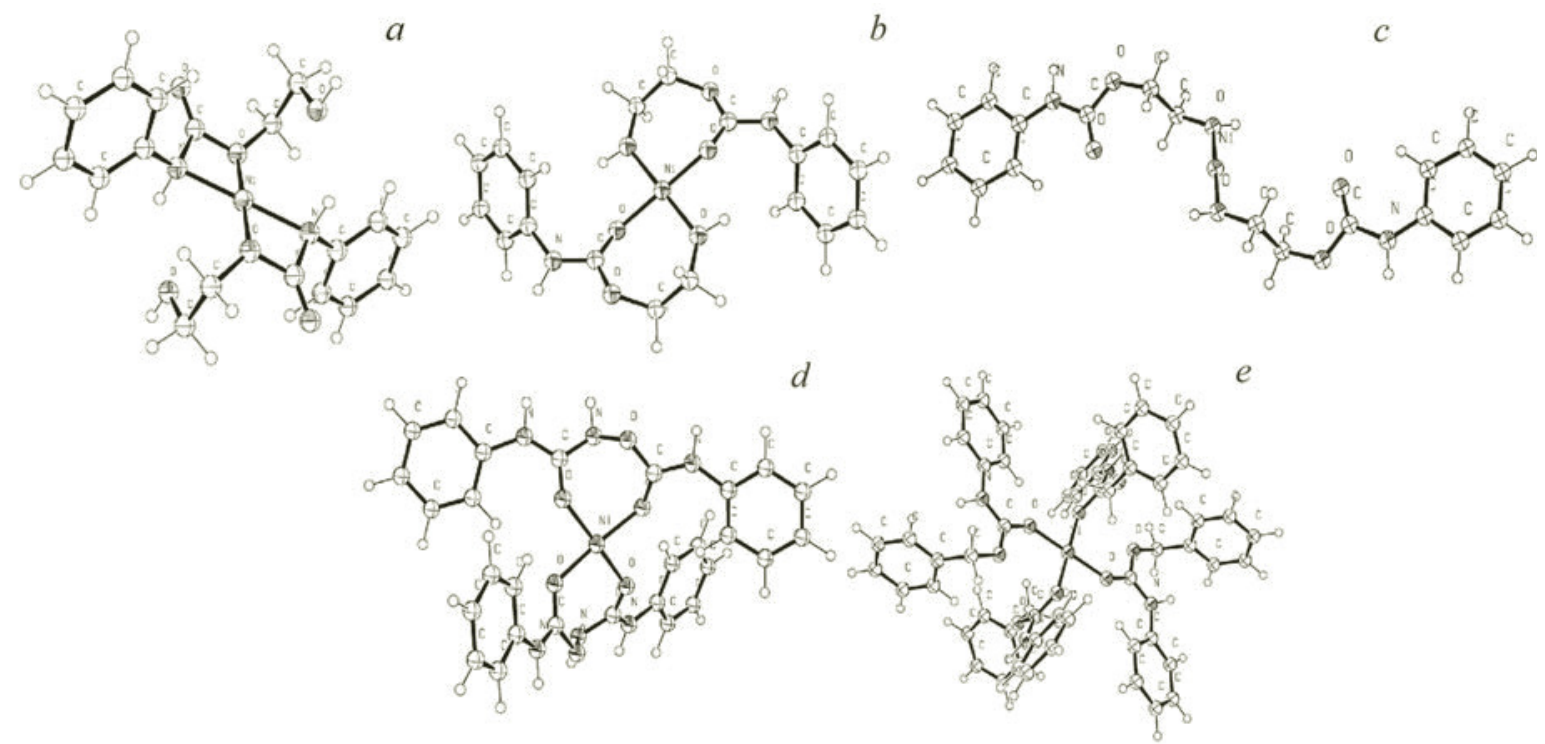

Fig. 5. Calculated structures of complexes $A$ (a), $B(\mathrm{~b}), C$ (c), $D$ (d), and $E$ (e).

with the $\mathrm{Ni}^{2+}$ ion. The complex is formed as a twolayer structure, in which the phenyl rings are located in almost parallel planes. The $\mathrm{Ni}^{2+}$ ion in complex $B$ shown in Fig. $5 \mathrm{~b}$ is bonded to the oxygen atoms of the carbonyl and hydroxyl groups. In this case, the complex has similar structure. The $\mathrm{Ni}^{2+}$ ion in complex $C$ is coordinated with the oxygen atoms of the terminal hydroxyl groups. In this case, the fragment is formed as a chain. Some structural and energy characteristics of complexes $A, B$, and $C$ given in Table 3 suggest that complex $B$ has the lowest energy of the three models $(A, B$, and $C$ ). The nickel ion in complex $B$ is coordinated with the oxygen atoms of the carbonyl and hydroxyl groups. Complex $A$, in which the nickel ion is coordinated with the oxygen and nitrogen atoms of the urethane carbonyl and amide fragments, and complex $C$, in which the nickel ion coordinates with the hydroxyl group oxygen atoms, have higher energy. 
TABLE 3. Calculated Energy and Structural Characteristics of Complexes $A, B$, and $C$

\begin{tabular}{|l|c|c|c|}
\hline \multicolumn{1}{|c|}{ Parameter } & Complex $A$ & Complex $B$ & Complex $C$ \\
\hline Relative energy, kJ/mole & 235 & 0 & 297 \\
\hline \multirow{2}{*}{ Internuclear distances $r(\mathrm{Ni} \ldots$..O) or $r(\mathrm{Ni} . . \mathrm{N}), \AA$} & 1.933 & 1.866 & 1.893 \\
& 1.974 & 1.907 & 0.541 \\
\hline \multirow{2}{*}{ Bond orders } & 0.462 & 0.661 & \multirow{2}{*}{0.569} \\
\hline
\end{tabular}

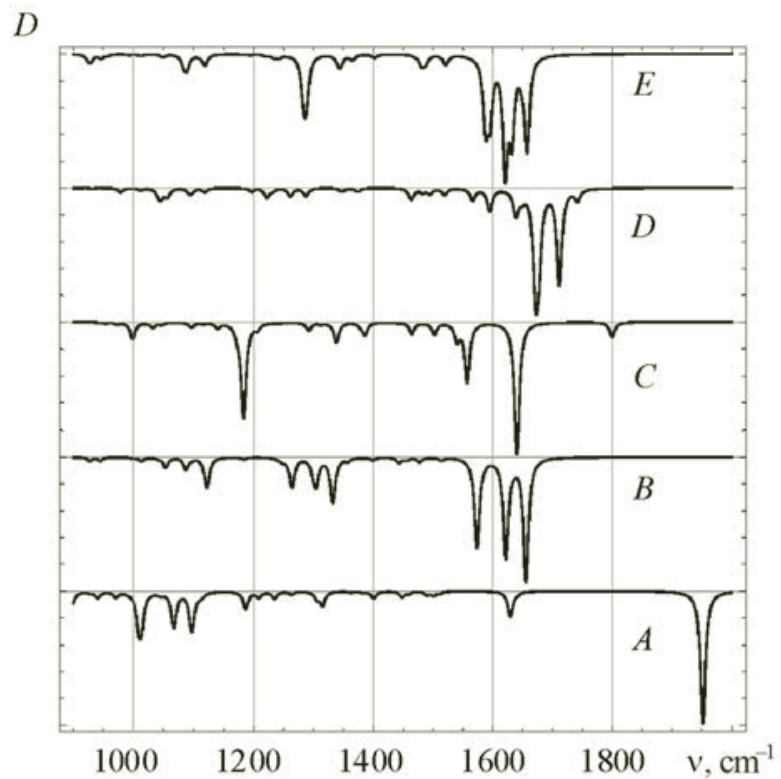

Fig. 6. Vibrational spectra calculated using the B3LYP/Stuttgart ECP10MDF + cc-pVDZ approximation for complexes $A-E$ of the $\mathrm{Ni}^{2+}$ ion with PUF fragments at $2000-900 \mathrm{~cm}^{-1}$.

These results are partially confirmed by the experimental results of Liu et al. [7], whose spectral data indicate that the heavy metal ions coordinate with the carbonyl group oxygen atoms. From the viewpoint of coordination bond formation, complexes $A, B$, and $C$ have similar characteristics: coordination bond lengths $1.86-1.98 \AA$ and Mulliken bond orders $0.46-0.66$. Complex $D$ shown in Fig. $5 \mathrm{~d}$ is formed by a nickel cation and two typeII PUF fragments. In this case, the nickel cation is coordinated with the oxygen atoms of the urethane and urea groups. This structure serves as a model for complex formation involving these groups belonging to a single PUF chain. The structural characteristics of complex $D$ are similar to those given above: $r(\mathrm{Ni} \ldots \mathrm{O})=1.896 \AA$ (coordination of the urea group), $r(\mathrm{Ni} \ldots \mathrm{O})=1.900 \AA$ (coordination of the urethane group), bond orders 0.617 and 0.582 . Complex $E$ shown in Fig. 5e formed by a nickel ion and four identical type III fragments containing one urethane group and two phenyl groups has the most complicated threedimensional structure. The coordination bond lengths are 1.884 and $1.904 \AA$ and the bond orders are 0.586 and 0.592 .

The vibrational IR spectra of the complexes calculated using the harmonic approximation are given in Fig. 6 and some calculated vibrational frequencies are given in Table 4 . The most characteristic feature of the spectrum calculated for complex $A$ is the extremely significant shift of the amide I band toward shorter wavelengths by $\sim 150 \mathrm{~cm}^{-1}$. This finding is attributed to "strengthening" of the carbon bond as the result of flow of electron density from the $-\mathrm{O}-\mathrm{C}(\mathrm{O})-\mathrm{N}$ - fragment during complex formation involving the nitrogen and oxygen atoms. This result was not supported by the experimental data and is apparently an artefact. Thus, the IR spectrum of sample 3 (Fig. 2) obtained as a result of the adsorption of the nickel salt from aqueous solution does not show any differences in this region from the spectrum of starting sample 2 . Thus, analysis of the calculated spectrum suggests that complex formation with the participation of nitrogen atoms and an ester oxygen atom is unlikely.

Electron density redistribution between the ringforming bonds in complex $B$ occurs due to the formation of rings containing a nickel ion (Figs. 5 and 6$)$. As a result, the frequencies of the amide $\mathrm{I}$ band $(\mathrm{C}=\mathrm{O}$ stretching vibration) and 
TABLE 4. Vibrational Frequencies $\left(\mathrm{cm}^{-1}\right)$ of Functional Groups in Complexes of the $\mathrm{Ni}^{2+}$ Ion with PUF Fragments Calculated in the B3LYP/Stuttgart ECP10MDF + cc-pDVZ Approximation

\begin{tabular}{|c|c|c|c|c|c|}
\hline Assignment & Complex $A$ & Complex $B$ & Complex $C$ & Complex $D$ & Complex $E$ \\
\hline$v(\mathrm{OH})$ & 3764 & 3683 & 3746 & - & - \\
\hline $\begin{array}{c}v(\mathrm{NH}) \\
\text { (Amide A) }\end{array}$ & 3398 (Urt) & 3560 (Urt) & 3547 (Urt) & $\begin{array}{c}3558 \text { (Urt) } \\
3553 \text { (Urt + Ura), } \\
3516 \text { (Ura) }\end{array}$ & 3601,3552 (Urt) \\
\hline $\begin{array}{c}v(\mathrm{C}=\mathrm{O}) \\
\text { (Amide I) }\end{array}$ & 1951 (Urt) & 1677,1665 (Urt) & 1800 (Urt) & $\begin{array}{c}1741 \text { (Urt + Ura), } \\
1711 \text { (Urt), } \\
1677 \text { (Urt + Ura) }\end{array}$ & $\begin{array}{c}1704,1657 \\
1632,1621 \text { (Urt) }\end{array}$ \\
\hline $\begin{array}{c}v(\mathrm{CN})+\rho(\mathrm{NH}) \\
(\text { Amide II })\end{array}$ & 1501 (Urt) & 1578,1567 (Urt) & 1566,1557 (Urt) & $\begin{array}{l}1598 \text { (Urt + Ura), } \\
1565 \text { (Urt + Ura) }\end{array}$ & 1596,1589 (Urt) \\
\hline$v(\mathrm{CN})+\rho(\mathrm{NH})+v(\mathrm{CC})(\mathrm{Ph})$ & 1398 (Urt) & 1404 (Urt) & 1503 (Urt) & $\begin{array}{c}1496 \text { (Ura), } \\
1466 \text { (Urt) }\end{array}$ & 1402,1397 (Urt) \\
\hline $\begin{array}{c}\delta(\mathrm{NH})+v(\mathrm{CN}) \\
\quad(\text { Amide III })\end{array}$ & 1305 (Urt) & 1299 (Urt) & 1206, 1183 (Urt) & $\begin{array}{c}1287 \text { (Ura), } \\
1261 \text { (Urt), } \\
1232 \text { (Urt + Ura) }\end{array}$ & 1271,1255 (Urt) \\
\hline$v\left(\mathrm{O}-\mathrm{CH}_{2}\right)$ & 1013 & 1133 & 1097 & - & 1088,1080 \\
\hline$v(\mathrm{CN})+v(\mathrm{C}=\mathrm{O})+v(\mathrm{CO})$ & 983, 971 (Urt) & 990 (Urt) & 972 (Urt) & $\begin{array}{c}981 \text { (Urt + Ura), } \\
880 \text { (Urt), } \\
848 \text { (Ura) }\end{array}$ & $\begin{array}{l}\text { 946, 929, } \\
881 \text { (Urt) }\end{array}$ \\
\hline $\mathrm{Ni} \ldots \mathrm{O}(\mathrm{Ni} \ldots \mathrm{N})$ & $\begin{array}{l}523(\mathrm{~N}) \\
471(\mathrm{O})\end{array}$ & $\begin{array}{l}664(\mathrm{H}) \\
548(\mathrm{Urt})\end{array}$ & $514(\mathrm{H})$ & $\begin{array}{c}516,471, \\
450,442 \text { (Urt + Ura) }\end{array}$ & $\begin{array}{c}533,495, \\
483,459 \text { (Urt) }\end{array}$ \\
\hline
\end{tabular}

Note. Urt) urethane group, Ura) urea group, Ph) phenyl group, H) hydroxyl group; F) free form (or dilute solution), A) associated form (or solid state).

the complex vibration $v(\mathrm{CN}+\rho(\mathrm{NH})+v(\mathrm{CC})$ are reduced and the frequencies of the amide III band and stretching vibrations of the $\mathrm{O}-\mathrm{C}$ bond containing an ester oxygen atom and methylene group carbon are increased (see Table 4). These results appear to be realistic.

The calculated spectrum of complex $D$ shows the following changes relative to the spectrum of fragment II: the carbonyl absorption band of the urethane and urea groups are shifted toward longer wavelengths from 1866 and $1820 \mathrm{~cm}^{-1}$ to 1741,1711 , and $1677 \mathrm{~cm}^{-1}$. The strong amide II absorption band found in the spectrum of the fragment at $1554 \mathrm{~cm}^{-1}$ is split in the spectrum of the complex into bands at 1598 and $1565 \mathrm{~cm}^{-1}$. Other absorption bands also underwent shifts in frequency and intensity. The major changes in the experimental IR spectrum of sample 3 (Fig. 2) are related precisely to this vibration range $\left(1550-1750 \mathrm{~cm}^{-1}\right)$.

Of all the models examined, the most significant shift toward longer wavelengths of the amide I absorption bands is found for complex $E$ : the strongest of these bands $\left(1632\right.$ and $\left.1621 \mathrm{~cm}^{1}\right)$ are shifted toward the region of the phenyl ring $\mathrm{C}-\mathrm{C}$ stretching vibrations and are partially overlapped by the latter. The amide II band in the spectrum of complex $E$ is shifted toward shorter wavelengths relative to its position in the spectrum of fragment III in complete accord with the experimental data [22] for the free and associated amide forms. On the whole, the calculated spectral characteristics of complex $E$ are in greatest agreement with the experimental data for the condensed phase relative to the other models of the complex structure.

Conclusions. The urethane foam adsorbent Penopurm ${ }^{\circledR}$ may be considered a bifunctional adsorbent since it is capable of extracting not only nonpolar compounds such as petroleum products and other hydrophobic hydrocarbons from aqueous solution but also $3 d$-metal cations. Analysis of the structural models and vibrational IR spectra calculated in the B3LYP/ Stuttgart ECP10MDF + cc-pVDZ approximation indicate a possible interaction of functional groups of polyurethane foam with $\mathrm{Ni}^{2+}$ cations in the adsorption of these ions from aqueous solution. The formation of coordination bonds is achieved primarily with the urethane and urea group carbonyls as well as the oxygen atoms of the terminal hydroxyl groups. Some spectral criteria were discovered, which indicate the predominant interaction of the $\mathrm{Ni}^{2+}$ ions with the various fragments of the polyurethane foam structure. Structural models were proposed, which give the best accord with the experimental data. 
Thus, use of comparatively simple models of the polyurethane fragments in quantum chemical calculations reveal the major features of the interaction of $3 d$-metal ions with polyurethane foam adsorbents.

\section{REFERENCES}

1. A. A. Berlin and F. A. Shutov, The Chemistry and Technology of GasFilled HighMolecularWeight Polymers [in Russian], Nauka, Moscow (1980).

2. Certificate No. 23965 (October 20, 2006) for Trademark Penopurm [in Russian].

3. M. A. Ksenofontov, L. E. Ostrovskaya, L. N. Vasil'evskaya, V. S. Vasil'eva, O. O. Gavrilenko, and A. S. Khatenko, Materialy, Tekhnologii, Instrumenty, 12, No. 2 77-80 (2007).

4. M. A. Ksenofontov, L. E. Ostrovskaya, E. Yu. Bobkova, L. I. Vasil'evskaya, and V. S. Vasil'eva, Voda: Khimiya Ékologiya, No. 6, 76-80 (2015).

5. S. G. Dmitrienko and Yu. A. Zolotov, Usp. Khim., 72, No. 2, 180-196 (2002).

6. S. G. Dmitrienko and V. V. Apyari, Polyurethane Foams. Adsorption Properties and Applications in Chemical Analysis [in Russian], Krasand, Moscow (2009).

7. X. Liu, Y. Zhao, Z. Liu, D. Wang, J. Wu, and D. Xu, J. Mol. Struct., 892, 200-204 (2008).

8. G. A. Pitkevich, M. B. Shundalau, M. A. Ksenofontov, and D S. Umreiko, Global J. Analyt. Chem., 2, 114-124 (2011).

9. M. B. Shundalau, A. I. Komyak, A. P. Zazhogin, and D. S. Umreiko, Zh. Prikl. Spektrosk., 79, 27-36 (2012) [J. Appl. Spectrosc., 79, 22-30 (2012)].

10. M. B. Shundalau, A. I. Komiak, A. P. Zajogin, and D. S. Umreiko, J. Spectrosc. Dyn., 3, 4 (2013).

11. M. W. Schmidt, K. K. Baldridge, J. A. Boatz, S. T. Elbert, M. S. Gordon, J. H. Jensen, S. Koeski, N. Matsunaga, K. A. Matsunaga, K. A. Nguyen, S. J. Su, T. L. Windus, M. Dupuis, and J. A. Montgomery, Jr., J. Comp. Chem., 14, 1347-1363 (1993).

12. A. D. Becke, J. Chem. Phys., 98, 5648-5652 (1993).

13. C. Lee, W. Yang, and R. G. Parr, Phys. Rev. B, 37, 785-789 (1988).

14. P. J. Stephens, F. J. Devlin, C. F. Chabalowski, and M. J. Frisch, J. Phys. Chem., 98, 11623-11627 (1994).

15. M. Dolg, U. Wedig, H. Stoll, and H. Preuss, J. Chem. Phys., 86, 866-872 (1987).

16. T. H. Dunning, Jr., J. Chem. Phys., 90, 1007-1023 (1989).

17. https://bse.pnl.gov/bse/portal

18. D. Feller, J. Comp. Chem., 17, 1571-1586 (1996).

19. K. L. Schuchardt, B. T. Didier, T. Elsethagen, L. Sun, V. Gurumoorthi, J. Chase, J. Li, and T. L. Windus, J. Chem Inf. Model., 47, 1045-1052 (2007).

20. L. J. Farrugia, J. Appl. Cryst., 30, 565 (1997).

21. C. H. Giles, T. H. MacEwan, S. N. Nakhwa, and D. Smith, J. Chem. Soc., 3973-3993 (1960).

22. R. M. Silverstein, F. X. Webster, and D. J. Kiemle, Spectrometric Identification of Organic Compounds, Wiley \& Sons, Inc. (2005). 